\title{
The Role of Social Networks During the COVID-19 Lockdown: Real-Life Social Distancing Vs Virtual Interactions
}

\author{
Donata Tania Vergura ${ }^{1}$, Beatrice Luceri ${ }^{1}$, Cristina Zerbini ${ }^{1}$ \\ ${ }^{1}$ Department of Economics and Management, University of Parma, Parma, Italy \\ Correspondence: Donata Tania Vergura, Department of Economics and Management, University of Parma, \\ Parma, Italy, Via J.F. Kennedy 6, 43125 Parma. Italy. E-mail: donatatania.vergura@unipr.it
}

Received: February 26, 2021

Accepted: March 16, 2021

Online Published: April 19, 2021

doi:10.5539/ijbm.v16n5p133

URL: https://doi.org/10.5539/ijbm.v16n5p133

\begin{abstract}
Online social networks have become one of the most widely used sources of information in the world and also an important part of our daily life. A huge boost to their spreading came with the outbreak of the COVID-19 pandemic. As social distancing and lockdown orders due to COVID-19 health emergency grew more pervasive, individuals began to spend more time online and to use social networks (SNs) to keep up to date regarding the spread of pandemic and also to maintain communication with friends and family and reduce isolation. Given these evidences, the present study aims to investigate the social supporting role of SNs during the pandemic emergency. Specifically, it intends to analyze (a) the use of SNs as a means of interaction in the face of the social containment imposed by the COVID-19 spreading, and (b) the factors (homophily, trust, loneliness, and emotional instability) that affect such use. An online survey with a sample of 194 Italian people was conducted. Structural equation modelling was used to estimate the model proposed. Results revealed that sense of belonging to SNs had a strong impact on search for social support and is, in turn, positively influenced by trust in SNs and homophily. Emotional instability also increased the search for social support. The study contributes both theoretically and empirically to the understanding of the role of SNs in influencing individual behavior. As the use of SNs continues to spread around the world, understanding why consumers rely in SNs and what gratifications they receive from them is undoubtedly of interest for both academics and practitioners.
\end{abstract}

Keywords: COVID-19, social networks, sense of belonging, emotional state, trust, homophily

\section{Introduction}

In 2020, the world was hit by a terrible pandemic. In a few months, the Chinese health emergency linked to the spread of COVID-19 (the disease caused by the Severe Acute Respiratory Syndrome Corona virus 2) has evolved into a global pandemic that has led to a humanitarian, social and economic crisis whose effects are still difficult to assess (e.g., Laborde, Martin, \& Vos, 2020; McKibbin \& Fernando, 2020; Lucchese \& Pianta, 2020). A lot of people have died and the health care systems of many countries have come close to collapse. Among the measures governments have taken to counter the COVID-19 pandemic, social distancing and isolation have been widely introduced. Lockdown and social distancing measures have suddenly changed the ways in which individuals lived and worked, and stopped many manufacturing activities. People were asked to stay at home and socially isolate themselves to prevent being infected (Rossi et al., 2020). Whole sectors, such as air travel, tourism, restaurants, transportation, and schools have completely stopped (Lucchese \& Pianta, 2020).

As a consequence of these measures, many scholars have been interested in the psychological consequences of a complete or near-complete lockdown, finding that it is associated with a wide range of psychiatric comorbidities including anxiety, panic, depression, and trauma-related disorders (e.g., Cullen, Gulati, \& Kelly, 2020; Killgore, Cloonan, Taylor \& Dailey, 2020; Orgilés, Morales, Delvecchio, Mazzeschi, \& Espada, 2020; Qiu et al., 2020; Rossi et al., 2020). From an economic point of view, literature, research institutes and national governments have focused on the changes in market dynamics and, mostly, on the global crisis due to the pandemic (e.g., Ashraf, 2020; Maital \& Barzani, 2020; McKibbin \& Fernando, 2020; Nicola et al., 2020; Statista, 2020; World Bank, 2020). Finally, from a social perspective, the media usage among individuals to seek information regarding the spread of pandemic, the quarantine procedures, and medical information or general advices in order to decrease the spread of fears and uncertainty has been investigated (e.g., Basch et al., 2020; Kouzy et al., 2020; Saud, Mashud, \& Ida, 2020). Scholars have focused on online media and, specifically, on social media in order to 
investigate their use for seeking support and awareness about COVID-19 as well as their impact in misinformation. On the contrary, to the authors knowledge, the impact of social distancing and isolation on the ways individuals interact and communicate with each other in order to maintain their social relationships and - at least apparently - continue their routines appears less explored. The present study focuses on the social networks usage during the pandemic emergency in order to investigate their social support role. More specifically, it intends to analyze (a) the use of social networks as a means for interaction during the lockdown due to the COVID-19 emergency and (b) the factors that affect such use (homophily, trust, loneliness, and emotional state).

Social networks (SNs) and, more generally, social media platforms are amongst the most widely used sources of information in the world. In the plethora of Web 2.0 online communication channels, social networks stand out because they enhance the information sharing process by allowing consumers to chat in real time with each other. They are a way to connect to the online world to exchange (seek and give) information with families, friends and the general public.

When the COVID-19 pandemic has spread to entire nations, upending normal existence for much of the world's population, social media usage has surged once more. People were turned to social media for updates and social connection. Analytics company Sprinklr reported a record nearly 20 million mentions of coronavirus-related terms on March 112020 (Conn, 2020) and SNs have all experienced a double-digit increase in usage (Nabity-Grover, Cheung, \& Thatcher, 2020). Social media platforms have become helpful for the public to maintain communication with friends and family, to entertain and reduce isolation and boredom (Nabity-Grover et al., 2020; Pérez-Escoda, Jiménez-Narros, Perlado-Lamo-de-Espinosa, \& Pedrero-Esteban, 2020).

Given these evidences, the study aims to enrich the literature on this research area in order to shed light on the relationship between people and SNs and, specifically, on their use as a means for maintaining social relationships, finding support and concrete help.

The paper is organized as follows. In the next section the literature review and the proposed conceptual model are described. The Methodology section describes the data collection procedure and the analysis method. Finally, the results are presented and the theoretical and managerial implications are discussed.

\section{Research Framework and Conceptual Model}

In February 2004, Facebook was born and the era of social networks began. Although other SNs had already been created before, 2004 marked the transition to the Web 2.0 era. The term Web 2.0 had its origin in the name given to a series of Web conferences, first organized by publisher Tim O'Reilly in 2004. His intention was to distinguish a first phase of the Web - where the user was mostly passive - from a second phase characterized by widespread interactivity. Digital communication has become interactive and dialogues-based. Today everyone can be an online content producer and this evolution has been made possible above all thanks to social media.

Social media have been defined as group of Internet-based applications allowing users to conveniently and selectively interact with each other through the creation and exchange of user-generated content (Carr \& Hayes, 2015; Kaplan \& Haenlein, 2010). Within this general definition, there are various types of social media that need to be distinguished further. Among these, social network sites have gained tremendous traction as a popular online hangout spaces for both youth and adults (Boyd, 2010). Social networking sites are applications that enable users to connect by creating personal information profiles, inviting friends and colleagues to have access to those profiles, and sending e-mails and instant messages between each other (Kaplan \& Haenlein, 2010). The term emphasizes the relational and sharing aspect of the medium. People flock to SNs to socialize with their friends and acquaintances, to share information with interested others, and to see and be seen (Boyd, 2010). The high levels of self-disclosure and social presence of SNs have enabled users to connect with other users by exchanging information, opinions, and thoughts (Chu \& Kim, 2011). And this system of relationships and sharing is built on a fundamental pillar that consists of the user-generated contents (UGC), namely on consumers' online information generation, distribution and retrieval.

As social distancing and lockdown orders due to COVID-19 health emergency grew more pervasive, individuals began to spend more time online. In addition to working reasons, they increasingly turned to digital platforms for entertainment and connection to others. In particular, the social distancing has led to a huge increase in the use of SNs to stay connected with family, friends, and colleagues (Kantar, 2020). Drawing on this evidence, this study intends to investigate the social support role played by SNs during periods of isolation and social distancing.

Cobb (1976) defined social support as the information leading the individual to believe that he or she is cared for, loved, esteemed, valued, and belonging to a network of communication and mutual obligation. Thoits (1982) synthesized by referring to "the degree to which a person's basic social needs are gratified through interaction 
with others".

Existing literature theorized that people join virtual communities to exchange social support (Hiltz \& Wellman, 1997; Mickelson, 1997; Ridings \& Gefen, 2004; Wellman \& Gulia, 1999). Frison and Eggermont (2015) highlighted how, in comparison to a face-to-face context, social support needs may be more easily expressed in a SNs context, as Facebook functions, such as status updating or instant messaging, facilitate the sharing of social support needs. Moreover, SNs comprise family members, close friends, colleagues, and friends of friends, whom users might not know well (or at all) offline. Due to this diversity of social ties on a single online platform, it is likely that SNs users receive more social support on these online platforms than offline (Trepte, Dienlin, \& Reinecke, 1015). On the contrary, Li, Chen and Popiel (2015) did not found a significant relationship between interaction on SNs and perceived social support.

The importance of social support following trauma, disaster or disease is reflected in several study (e.g., Bartone et al., 1989; Anderson \& Lyons, 2005; Pakenham et al., 1994). The spreading of a worldwide pandemic can be considered as a trauma for some individuals. Health emergencies such as epidemics can lead to detrimental and long-lasting psychosocial consequences, due to disease related fear and anxiety and to large-scale social isolation (Cullen et al., 2020; Killgore et al., 2020; Orgilés et al., 2020; Qiu et al., 2020; Rossi et al., 2020). In the context of complete or near-complete lockdown due to the COVID-19 health emergency, SNs may have represented a useful tool that individuals have used to "create" a sense of normality and seek that social support that they could not get in the real-life environment due to social distancing measures.

Starting from this reasoning, a better understanding of the social supporting role of SNs during the pandemic emergency and, more in detail, of the dimensions which affect this role is undoubtedly of interest for both academics and practitioners. In order to suit the research objective of the study, the conceptual model shown in Figure 1 was proposed. Five focal antecedent variables of search for social support in SNs were identified. The selection was made according to the relevant literature and to their expected relevance in the context under investigation.

The first set of variables pertained to the individual confidence and involvement with SNs, measured in terms of trust and sense of belonging. Sense of belonging is an affective or internal evaluative feeling or perception (Hageyrty Lynch-Sauer, Patusky, Bouwsema, \& Collier, 1992). Anant (1966) defined it as a "sense of personal involvement in a social system so that persons feel themselves to be an indispensable and integral part of the system". In the context of SNs, sense of belonging is recognized as the psychological state of being part of the community in an online social network that influences users' attitudes, stickiness and subsequent usage behaviors (Cheung, Chiu, \& Lee, 2011; Hsu \& Liao, 2014; Lin, Fan, \& Chau, 2014). Users develop a sense of belonging to SNs via managing personal relationships and developing feelings of membership, identification, and shared socio-emotional ties as a result of continued exposure and usage of the system (Lin et al., 2014). Liu and Guo (2015) figured belongingness at the core of user's decision to continued use of social media. Similarly, other authors highlighted its significant role as affective antecedent of usage habit and continuance behavior within the social media communities (e.g., Lin et al. 2014; Liu, Shao, \& Fan, 2018). Furthermore, sense of belonging reflects a high willingness of members to care about one another (Zhao, Lu, Wang, Chau, \& Zhang, 2012). In light of these evidences, the sense of belongingness to a social network is expected to affect its use as a means of social support, especially in a context of deprivation of physical social relationships. Therefore, the following hypothesis is formulated:

\section{H1: Sense of belonging positively influences search for social support in SNs.}

Rotter (1967) defined trust as "an expectancy held by an individual or a group that the word, promise, verbal or written statement of another individual or group can be relied upon". In other words, it is a belief or expectation about the other (trusted) party, or a behavioral intention or willingness to depend or rely on another party (e.g., Mayer, Davis, \& Schoorman, 1995; Rousseau, Sitkin, Burt, \& Camerer, 1998). Grabner-Kräuter and Bitter (2013) referred to a "mental short-cut" that enables users to promptly engage in trust-related behaviors, such as the provision of personal information. Trust is a fundamental aspect in virtual communities since they are largely anonymous and cannot count on face-to-face contact. Members may have greater concerns about the truthfulness of others and lack of trust among participants is a major barrier in establishing virtual communities (Blanchard, 2008; Lin, 2008). On the contrary, trustworthiness of a social media site may provide its members an expectation of successful operation and reduce uncertainty stemmed from more dynamic nature of social media sites (Liu \& Guo, 2015).

The literature has highlighted the role of trust in increasing the users' propensity to use social networking sites (e.g., Chu \& Kim, 2011; Ridings, Gefen, \& Arinze, 2002; Zhao et al., 2012). Starting form this evidence, it is 
reasonable to assume that trust in SNs positively affects their use as sources of social support. In situations of uncertainty, trust can serve as an important mechanism to reduce it and mitigate the complexity of exchanges and relationships (Grabner-Kräuter \& Bitter, 2013). On the base of this reasoning, in situations of uncertainties regarding the consequences and the persistence of the pandemic and, above all, of lack of real-life social relationships during periods of social containment, a high trust in SNs can increase their use as a means of social support. This leads to the formulation of the following hypothesis:

\section{H2: Trust in SNs positively influences search for social support in SNs.}

Homophily is another construct that is worth consideration in the conceptualization of consumers' search for social support in SNs. Homophily is defined as the degree to which individuals who interact with one another are congruent or similar in certain attributes (Rogers \& Bhowmik, 1970). This may cause more enjoyment and time spent in interacting with similar people (Zhao et al., 2012). Prior research has suggested that in virtual communities, members are more willing to interact and share information with similar people (e.g., Kim, Kandampully, \& Bilgihan, 2018; Mainolfi \& Vergura, 2019; Steffes \& Burgee 2009; Vergura, Luceri, \& Zerbini, 2021). The presence of similar values, preferences, and lifestyles can facilitate individuals' external information search process because it reduces uncertainty (Chu \& Kim, 2011). Given these considerations, the present study aims to test the effect of perceived homophily with SNs' contacts on seeking social support. Similarity between the individuals in a community can lead to a greater propensity to seek social support in that community, compared to what might be expected between dissimilar individuals:

\section{H3: Homophily positively influences search for social support in SNs.}

Both trust and homophily have found to be correlated with sense of belonging. Some scholars have highlighted that trust fosters a sense of belonging in online communities (e.g., Lin, 2008; Liu \& Guo, 2015; Zhao, 2012). Zhao (2012) also found that perceived similarity with other members is positively related to sense of belonging, which in turn mediates the effect of homophily and trust on intention to get knowledge. The present study intends to support the existence of these relationships also in the context of getting social support. Therefore, the following hypotheses are formulated:

H4: Trust in SNs positively influences sense of belonging to SNs.

H5: Homophily positively influences sense of belonging to SNs.

H6: Sense of belonging mediates the relationship between (H6a) trust and search for social support and (H6b) homophily and search for social support.

The last set of variables pertains to the emotional states of individuals, measured as emotional instability and loneliness. Emotion can be defined as a complex series of psychophysical stimulate which invokes either a positive or a negative response, physical reactions, and facial expressions (Tang et al., 2011). Emotional states often vary enormously over very short periods of time. Underwood and Froming (1980) argue that there are some people typically more emotionally stable and others who can generally be categorized as unstable. Emotional instability is a personality trait which refers to the tendency to experience mood swings and negative emotions such as guilt, anger, anxiety, and depression (Kosinski, Bachrach, Kohli, Stillwell, \& Graepel, 2014). The psychological literature provides some examples of the relationship between personality traits and users' behavior in an online setting (e.g., Kosinski et al., 2014; Marcus, Machilek, \& Schütz, 2006; Moody, 2001; Morahan-Martin, 1999; Vazire \& Gosling, 2004) highlighting how this can be influenced, among other dimensions, by emotional instability and loneliness. Loneliness is described as an emotional state with unpleasant, negative connotations. It implies a need for another person or group that has been disrupted and is discussed in the context of absence or loss (Copel, 1988; Russell, Cutrona, Rose, \& Yurko, 1984; Welt, 1987). Even before the pandemic some scholars had highlighted the use of social networks to cope with negativity and loneliness (Radovic, Gmelin, Bradley, 2017; Şar, Göktürk, Tura, \& Kazaz, 2012). And this was also confirmed during the lockdown measures due to the COVID-19 emergency (Cauberghe, Wesenbeeck, De Jans, Hudders, \& Ponnet, 2020). There are growing concerns that lockdown measures due to the COVID-19 pandemic could lead to a rise in loneliness, which is recognized as a major public health concern $(\mathrm{Bu}$, Steptoe, \& Fancourt, 2020; Killgore et al., 2020). Since social isolation can lead to feelings of emotional instability and loneliness, the use of social networks can be used as a constructive coping strategy to deal with these feelings (Cauberghe et al., 2020). This study aims to increase knowledge on this issue. The tendency to be emotionally unstable and the feeling of loneliness can affect the users' tendency to seek social support in virtual communities when real-time relationships are almost zero. In light of these reasoning, the following hypotheses are formulated:

H7: The greater the emotional instability, the greater the search for social support in SNs. 
H8: The greater the loneliness, the greater the search for social support in SNs.

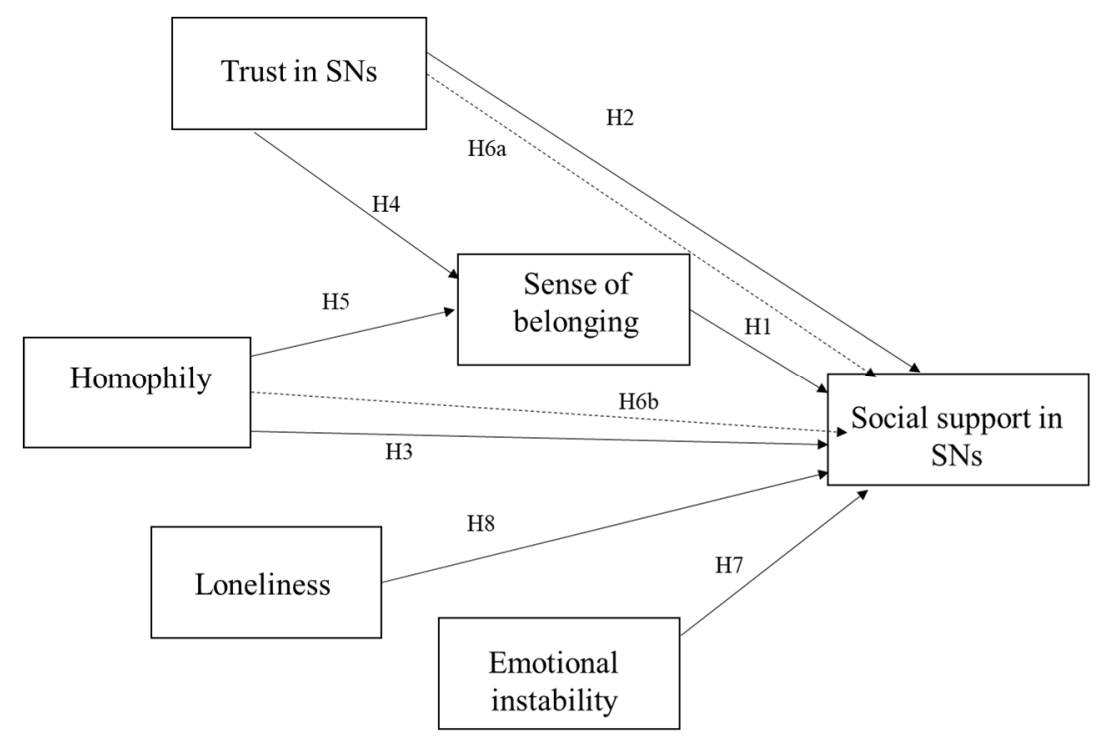

Figure 1. Research model and hypotheses

Note. Mediated relationships are represented in dotted lines.

\section{Method}

To test the proposed model, a self-administered questionnaire was filled in online by a sample of Italian users. Dara were collected between April 29 and May 6 2020. All participants were informed that the study was on a voluntary basis and that information provided would be kept confidential. The survey was developed using the free software Google Forms. Respondents were recruited online thanks to the publication of an informative post on some SNs. They were immediately asked if they had an account on a social network. Only those who answered "yes" were able to complete the questionnaire. The final sample size was 194.

Measures for the various constructs were adapted from previous research, with some amendments made to fit the context of the present research.

Sense of belonging was measured through the four items developed by Liu and Guo (2015). Measures for trust consisted of four items adapted from Fogel and Nehmad (2009). Homophily was measured through the four items proposed by Kusumasondjaja (2015), while the 7-item Crisis Support Scale by Elklit et al. (2001) was used for detecting social support in SNs. Loneliness was measured using the UCLA Loneliness Scale (ULS-8) (Wu \& Yao, 2008). Finally, the Reactive 8-items subscale from the Mood Survey by Underwood and Froming (1980) was used for detecting emotional instability. All items were constructed using a 7-point anchored scale (from "completely disagree" to "completely agree"). Cronbach's alphas were used to assess the scales' internal consistency. The index was very high for each construct, ranging from 0.75 for loneliness to 0.91 for trust (see Table 1). In addition, demographic questions and SNs usage habit (SNs used) were included.

Structural equation modelling with maximum likelihood method was employed for the analysis of the conceptual model. Data analysis was performed using the IBM SPSS statistical software (SPSS Inc, Chicago, IL; release 25.0) and the LISREL software (release 8.80). 
Table 1. Measurement scales and reliability indices

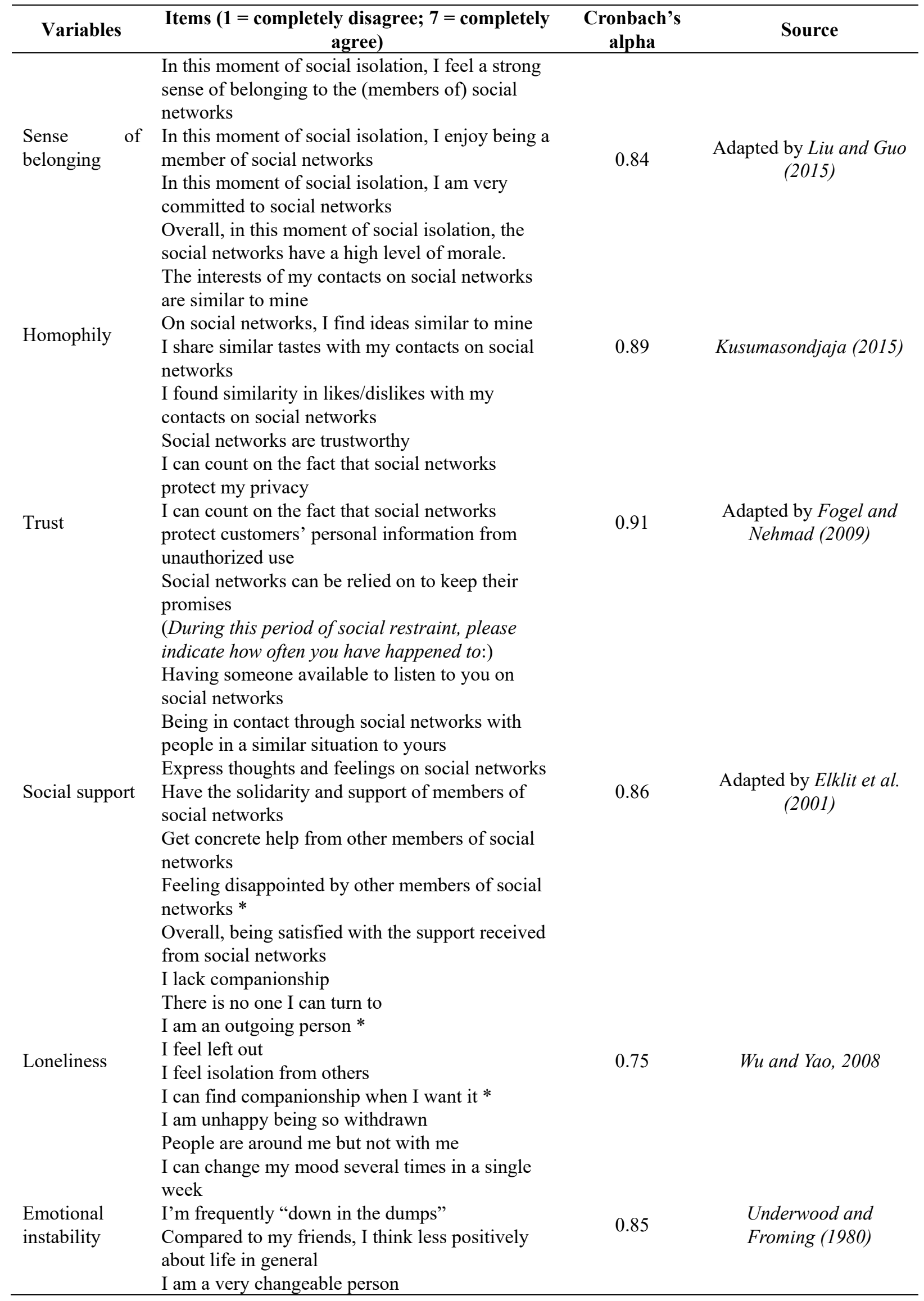




\begin{tabular}{llcl}
\hline Variables & Items $(\mathbf{1}=$ completely disagree; $7=$ completely \\
agree $)$ & $\begin{array}{c}\text { Cronbach's } \\
\text { alpha }\end{array}$ & Source \\
\hline & $\begin{array}{l}\text { I'm not as cheerful as most people } \\
\text { My friends often seem to feel I am unhappy }\end{array}$ & \\
I'm not often really elated & & \\
Sometimes my mood swing back and forth very & & \\
rapidly & & \\
\hline
\end{tabular}

\section{Results}

\subsection{Respondent Profile}

The sample was represented by $60 \%$ women and $40 \%$ men, with a mean age of $29(\min =18 ; \max =63)$. The respondents were well-educated: $41 \%$ had graduated or post-graduated and $50 \%$ completed high school; the remaining $9 \%$ had left school after the primary or secondary level. Out of the sample, $15 \%$ lives alone, $61 \%$ with parents and 24\% were married or cohabiting. The three most used SNs were Facebook, Instagram and Twitter.

\subsection{Research Results}

As the skew and kurtosis statistics showed that the normality assumption was violated $\left(\chi^{2}=2533.935, \mathrm{p}<0.001\right)$, the model was estimated using the Satorra-Bentler method (Satorra \& Bentler, 1994). The fit indices indicated an acceptable overall fit of the measurement model to the data: Satorra-Bentler scaled $\chi^{2}=744.366, \mathrm{df}=514, p$ $=0.000$, comparative fit index $(\mathrm{CFI})=0.986$, root mean square error of approximation (RMSEA) $=0.048$, normed fit index $(\mathrm{NFI})=0.897$, non-normed fit index $(\mathrm{NNFI})=0.962$ and standardized root mean square residual $(\mathrm{SRMR})=0.090$.

The analysis provided support for the H1 (Fig. 2). Sense of belonging to SNs significantly and positively influenced search for social support in these virtual communities $(\beta=0.606, p<0.01)$. On the contrary, the direct effects of trust and homophily on the use of SNs as a means of social support did not found support on the empirical data (H2 and $\mathrm{H} 3$ are not supported). However, these two variables act as antecedents of sense of belonging: greater trust in SNs and greater perceived similarities with their members translate in a higher sense of belonging, thus supporting H4 $(\beta=0.169, p<0.05)$ and $\mathrm{H} 5(\beta=0.386, p<0.01)$. Mediation analysis also showed that sense of belonging completely mediates the relationships between homophily and search for social support (indirect effect $=0.276 ; p<0.01 ; \mathrm{CI} 95 \%$ : $[0.092 ; 0,397]$ ), thus supporting H6b: perceived similarity with the other SN's members increased the sense of belonging, which in turn exerted a positive effect on seeking social support. On the contrary, the indirect effect of trust on the final dependent variable (H6a) did not found support in the mediation analysis. Finally, whit reference to the effect of emotional states, only emotional instability significantly increased the users' tendency to seek help in SNs (H8; $\beta=0.135, p<0.05)$. The effect of loneliness was found to be not significant (H7 not supported).

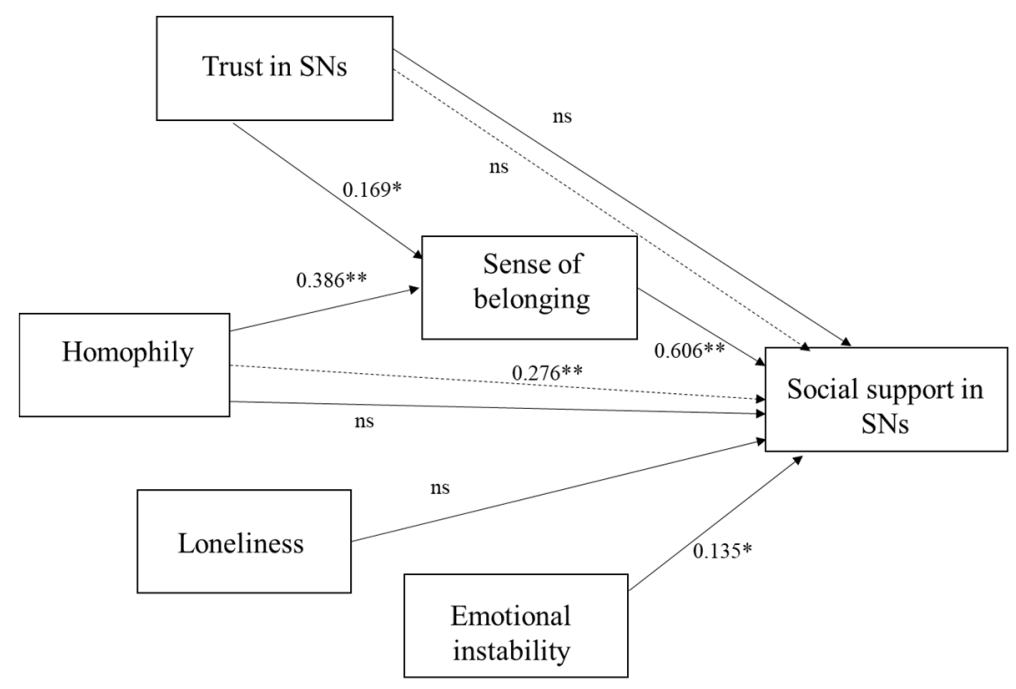

Figure 2. Structural model with standardized coefficients

Notes: $* p<0.05 ; * * p<0.01$, indirect relationships are represented in dotted lines 


\section{Conclusion}

Online social networks have recently increased at an exponential rate. This growth in popularity and membership has created a new world of collaboration and communication (Cheung et al., 2011). A huge boost to this spread came with the outbreak of the COVID-19 pandemic. Online platforms, in general, and social media in particular have become crucial for the individuals to gather information and keep up to date, for shopping and also to maintain communication with friends and family and reduce isolation.

The objective of this study was to explore the use of SNs as a source for social support during the total or partial absence of real-life interactions due to the pandemic emergency. The results showed that sense of belonging to SNs has a strong impact on search for social support and is, in turn, positively influenced by trust in SNs and homophily. When users perceive a similarity in certain attributes with the other members and consider SNs to be trustworthy, they will feel a higher belonging to the virtual community and, consequently, they will have higher tendency to search for support and concrete help. Among the other investigated antecedents of social support, emotional instability stands out. Mood swings affect the search for social support and increase it.

The study enriches the literature on social networks and provides practitioner some guidance for the understanding of their role in influencing individual behavior. At the theoretical level, it highlights a causal relationship path in which search for social support in SNs is directly and mainly guided by the sense of belonging to the online community and, indirectly, by homophily. Emotional state also influences the investigated behaviour through its emotional instability dimension rather than loneliness. Therefore, the study makes an important contribution to understanding which contextual factors can best predict why a person goes to SNs to seek social support.

Results of this study are also important to practitioners. From a managerial perspective, understanding the role of SNs in the consumer daily life may help companies to effectively incorporate these media as an integral and significant part of the marketing communication mix. Previous studies have already shown the effect of social media communication on purchase decisions (e.g., Goh, Heng \& Lin 2013; Park \& Cho, 2012; Pookulangara \& Koesler, 2011; Syrdal \& Briggs, 2018; Vergura, Luceri \& Zerbini, 2021; Zhu, Wang, He, \& Tian, 2020). This study aims to enrich this knowledge by extending the analysis to other aspects of the consumer behavior. Against this background, as the COVID-19 pandemic continues to spread around the world, and the use of social networks too, it is even more important for companies to understand why consumers use SNs and what gratifications they receive from them. Moreover, because of uncertainty about the economic environment and the increase in users' engagement with digital content, brands are increasing their use of organic content and decreasing their ad spend (Socialbakers, 2020). This means that owned and earned media, like SNs and online communities, are becoming more and more important.

If one of the reasons for using SNs is to receive social support, companies need to be aware of this in order to develop their marketing strategies accordingly. In a period like a lockdown, SNs can be a fundamental tool to stay close to consumers by creating the contents and offering the help they need. This means developing contents capable of satisfying the need for social support. Branded content marketing strategies, for example, can address this goal. An analysis carried out on 52 marketing campaigns from different industrial sectors and five European markets showed that, in March and April 2020, they were oriented to the "new needs of security and belonging" by focusing on safety, home, relationship with their loved ones and creation of a sense of belonging (Reply, 2021). In this way, companies have the opportunity to create a community and retain their followers.

The results of this study are a stepping stone towards future research. Despite the literature contribution, further research is recommended in order to generalize the results. Extended the investigation to larger samples and testing the proposed model in other countries would be appropriate. Moreover, the causal relationship between emotional instability and search for social support should be better explored. If it is true that emotional instability increases the use of SNs as social support, experiencing this support could in turn affect the emotional state by improving it. This could generate positive effects not only in virtual relationships but also in real-life relationships, as well as stimulate new needs and behaviors. Finally, a comparison between different SNs would be opportune in order to explore any differences in the social interaction dynamics.

\section{References}

Anant, S. S. (1966). The need to belong. Canada's Mental Health, 14(2), 21-27.

Anderson, I., \& Lyons, A. (2005). The effect of victims' social support on attributions of blame in female and male rape. Journal of Applied Social Psychology, 35(7), 1400-1417. https://doi.org/10.1111/j.1559-1816.2005.tb02176.x 
Ashraf, B. N. (2020). Economic impact of government interventions during the COVID-19 pandemic: International evidence from financial markets. Journal of Behavioral and Experimental Finance, 27, 100-371. https://doi.org/10.1016/j.jbef.2020.100371

Bartone, P. T., Ursano, R. J., Wright, K. M., \& Ingraham, L. H. (1989). The impact of a military air disaster on the health of assistance workers. Journal of Nervous and Mental Disease, 177(6), 317-328. https://doi.org/10.1097/00005053-198906000-00001

Basch, C. H., Hillyer, G. C., Meleo-Erwin, Z. C., Jaime, C., Mohlman, J., \& Basch, C. E. (2020). Preventive behaviors conveyed on YouTube to mitigate transmission of COVID-19: cross-sectional study. JMIR public Health and Surveillance, 6(2), 18807. https://doi.org/10.2196/18807

Blanchard, A. L. (2008). Test a Model of Sense of Virtual Community. Computers in Human Behavior, 24, 2107-2123. https://doi.org/10.1016/j.chb.2007.10.002

Boyd, D. (2010). Social Network Sites as Networked Publics: Affordances, Dynamics, and Implications. In Z. Papacharissi (Ed.), Networked Self: Identity, Community, and Culture on Social Network Sites (pp. 39-58). Routledge.

Bu, F., Steptoe, A., \& Fancourt, D. (2020). Who is lonely in lockdown? Cross-cohort analyses of predictors of loneliness before and during the COVID-19 pandemic. Public Health, 186, 31-34. https://doi.org/10.1016/j.puhe.2020.06.036

Carr, C. T., \& Hayes, R. A. (2015). Social media: Defining, developing, and divining. Atlantic Journal of Communication, 23, 46-65. https://doi.org/10.1080/15456870.2015.972282

Cauberghe, V., Van Wesenbeeck, I., De Jans, S., Hudders, L., \& Ponnet, K. (2020). How adolescents use social media to cope with feelings of loneliness and anxiety during COVID-19 lockdown. Cyberpsychology, Behavior, and Social Networking. https://doi.org/10.1089/cyber.2020.0478

Cheung, C. M., Chiu, P. Y., \& Lee, M. K. (2011). Online social networks: Why do students use facebook? Computers in Human Behavior, 27(4), 1337-1343. https://doi.org/10.1016/j.chb.2010.07.028

Chu, S.C., \& Kim, Y. (2011). Determinants of consumer engagement in electronic word-of-mouth (eWOM) in social networking sites, International Journal of Advertising, 30(1), 47-75. https://doi.org/10.2501/IJA-30-1-047-075

Cobb, S. (1976). Social support as a moderator of life stress. Psychosomatic medicine, 38, $300-314$. https://doi.org/10.1097/00006842-197609000-00003

Conn, G. (2020). Managing Brand Communication During Covid-19. Retrieved from https://blog.sprinklr.com/managing-brand-communication-covid-19

Copel, L. C. (1988). Loneliness: A conceptual model. Journal of Psychosocial Nursing and Mental Health Services, 26(1), 14-19. https://doi.org/10.3928/0279-3695-19880101-08

Cullen, W., Gulati, G., \& Kelly, B. D. (2020). Mental health in the Covid-19 pandemic. QJM: An International Journal of Medicine, 113(5), 311-312. https://doi.org/10.1093/qjmed/hcaa110

Elklit, A., Pedersen, S. S., \& Jind, L. (2001). The Crisis Support Scale: psychometric qualities and further validation. Personality and Individual Differences, 31, 1291-1302. https://doi.org/10.1016/S0191-8869(00)00220-8

Fogel, J., \& Nehmad, E. (2009). Internet social network communities: Risk taking, trust, and privacy concerns. Computers in Human Behavior, 25(1), 153-160. https://doi.org/10.1016/j.chb.2008.08.006

Frison, E., \& Eggermont, S. (2015). The impact of daily stress on adolescents' depressed mood: The role of social support seeking through Facebook. Computers in Human Behavior, 44, 315-325. https://doi.org/10.1016/j.chb.2014.11.070

Goh, K. Y., Heng, C. S., \& Lin, Z. (2013). Social media brand community and consumer behavior: quantifying the relative impact of user- and marketer-generated content. Information Systems Research, 24(1), 88-107. https://doi.org/10.1287/isre.1120.0469

Grabner-Kräuter, S., \& Bitter, S. (2013). Trust in online social networks: A multifaceted perspective. Forum for Social Economics, 44(1), 48-68. https://doi.org/10.1080/07360932.2013.781517

Hageyrty, B. M. K., Lynch-Sauer, J., Patusky, K. L., Bouwsema, M., \& Collier, P. (1992). Sense of belonging: A vital mental health concept. Archives of Psychiatric Nursing, 6(3), 172-177. 
https://doi.org/10.1016/0883-9417(92)90028-H

Hiltz, S. R., \& Wellman, B. (1997). Asynchronous learning networks as a virtual classroom. Communications of the ACM, 40(9), 44-49. https://doi.org/10.1145/260750.260764

Hsu, C., \& Liao, Y. (2014). Exploring the linkages between perceived information accessibility and microblog stickiness: The moderating role of a sense of community. Information \& Management, 51(7), 833-844. https://doi.org/10.1016/j.im.2014.08.005

Kantar, (2020). COVID-19 Barometer: Consumer attitudes, media habits and expectations. Retrieved from https://www.kantar.com/Inspiration/Coronavirus/COVID-19-Barometer-Consumer-attitudes-media-ha bits-and-expectations

Kaplan, A. M., \& Haenlein, M. (2010). Users of the world, unite! The challenges and opportunities of Social Media. Business horizons, 53(1), 59-68. https://doi.org/10.1016/j.bushor.2009.09.003

Killgore, W. D. S., Cloonan, S. A., Taylor, E. C., \& Dailey, N. S. (2020). Loneliness: A signature mental health concern in the era of COVID-19. Psychiatry Research, 290. https://doi.org/10.1016/j.psychres.2020.113117

Kim, S., Kandampully, J., \& Bilgihan, A. (2018). The influence of eWOM communications: An application of online social network framework. Computers in Human Behavior, 80, 243-254. https://doi.org/10.1016/j.chb.2017.11.015

Kosinski, M., Bachrach, Y., Kohli, P., Stillwell, D., \& Graepel, T. (2014). Manifestations of user personality in website choice and behaviour on online social networks. Machine Learning, 95(3), 357-380. https://doi.org/10.1007/s10994-013-5415-y

Kouzy, R., Abi Jaoude, J., Kraitem, A., El Alam, M. B., Karam, B., Adib, E., ... \& Baddour, K. (2020). Coronavirus goes viral: quantifying the COVID-19 misinformation epidemic on Twitter. Cureus, 12(3). https://doi.org/10.7759/cureus. 7255

Kusumasondjaja, S. (2015). Information quality, homophily, and risk propensity: Consumer responses to online hotel reviews. Journal of Economic, Business and Accountancy Ventura, 18(2), 241-252. https://doi.org/10.14414/jebav.v18i2.451

Laborde, D., Martin, W., \& Vos, R. (2020). Poverty and food insecurity could grow dramatically as COVID-19 spreads. International Food Policy Research Institute (IFPRI), Washington, DC.

Li, X., Chen, W., \& Popiel, P. (2015). What happens on Facebook stays on Facebook? The implications of Facebook interaction for perceived, receiving, and giving social support. Computers in human behavior, 51, 106-113. https://doi.org/10.1016/j.chb.2015.04.066

Lin, H. F. (2008). Determinants of successful virtual communities: Contributions from system characteristics and social factors. Information \& Management, 45(8), 522-527. https://doi.org/10.1016/j.im.2008.08.002

Lin, H., Fan, W., \& Chau, P. Y. K. (2014). Determinants of users' continuance of Social networking sites: A self-regulation perspective. Information \& Management, 51(5), 595-603. https://doi.org/10.1016/j.im.2014.03.010

Liu, C. T., \& Guo, Y. M. (2015). The Role of Sense of Belonging in Social Media Usage: A Tale of Two Types of Users. Asia Pacific Journal of Information Systems, 25(2), 211-233. https://doi.org/10.14329/apjis.2015.25.2.403

Liu, Q., Shao, Z., \& Fan, W. (2018). The impact of users' sense of belonging on social media habit formation: Empirical evidence from social networking and microblogging websites in China. International Journal of Information Management, 43, 209-223. https://doi.org/10.1016/j.ijinfomgt.2018.08.005

Lucchese, M., \& Pianta, M. (2020). The Coming Coronavirus Crisis: What Can We Learn? Intereconomics, 55, 98-104. https://doi.org/10.1007/s10272-020-0878-0

Mainolfi, G., \& Vergura, D. T. (2019). The role of fashion blogger credibility, homophily and engagement on followers' intentions to buy fashion products: Results of a binational study. In Proceedings of the Global Fashion Management Conference (pp. 11-14).

Maital, S., \& Barzani, E. (2020). The global economic impact of COVID-19: A summary of research. Samuel Neaman Institute for National Policy Research, 1-12.

Marcus, B., Machilek, F., \& Schütz, A. (2006). Personality in cyberspace: personal web sites as media for personality expressions and impressions. Journal of Personality and Social Psychology, 90(6), 1014-1031. 
https://doi.org/10.1037/0022-3514.90.6.1014

Mayer, R. C., Davis, J. H., \& Schoorman, F. D. (1995). An integrative model of organizational trust. The Academy of Management Review, 20(3), 709-734. https://doi.org/10.5465/amr.1995.9508080335

McKibbin, W., \& Fernando, R. (2020). The economic impact of COVID-19. Economics in the Time of COVID-19, 45.

Mickelson, K. D. (1997). Seeking social support: Parents in electronic support groups. In S. Kiesler (Ed.), Culture of the Internet (157-178). Mahawah, NJ: Lawrence Erlbaum Associates.

Moody, E. J. (2001). Internet use and its relationship to loneliness. Cyber Psychology and Behaviour, 4, 393-401. https://doi.org/10.1089/109493101300210303

Morahan-Martin, J. (1999). The relationship between loneliness and Internet use and abuse. CyberPsychology and Behavior, 2, 431-440. https://doi.org/10.1089/cpb.1999.2.431

Nabity-Grover, T., Cheung, C. M., \& Thatcher, J. B. (2020). Inside out and outside in: How the COVID-19 pandemic affects self-disclosure on social media. International Journal of Information Management, 55, 102188. https://doi.org/10.1016/j.ijinfomgt.2020.102188

Nicola, M., Alsafi, Z., Sohrabi, C., Kerwan, A., Al-Jabir, A., Iosifidis, C., ... \& Agha, R. (2020). The socio-economic implications of the coronavirus and COVID-19 pandemic: a review. International Journal of Surgery, 78, 185-193. https://doi.org/10.1016/j.ijsu.2020.04.018

Orgilés, M., Morales, A., Delvecchio, E., Mazzeschi, C., \& Espada, J. P. (2020). Immediate psychological effects of the COVID-19 quarantine in youth from Italy and Spain. Frontiers in Psychology, 11, 2986. https://doi.org/10.3389/fpsyg.2020.579038

Pakenham, K. I., Dadds, M. R., \& Terry, D. J. (1994). Relationship between adjustment to HIV and both social support and coping. Journal of Consulting and Clinical Psychology, 62(6), 1194. https://doi.org/10.1037/0022-006X.62.6.1194

Park, H., \& Cho, H. (2012). Social network online communities: information sources for apparel shopping. Journal of Consumer Marketing, 29(6), 400-411. https://doi.org/10.1108/07363761211259214

Pérez-Escoda, A., Jiménez-Narros, C., Perlado-Lamo-de-Espinosa, M., \& Pedrero-Esteban, L. M. (2020). Social Networks' Engagement During the COVID-19 Pandemic in Spain: Health Media vs. Healthcare Professionals. International journal of environmental research and public health, 17(14), 5261. https://doi.org/10.3390/ijerph17145261

Pookulangara S., \& Koesler K. (2011). Cultural influence on consumers' usage of social networks and its' impact on online purchase intentions. Journal of Retailing and Consumer Services, 18(4), 348-354. https://doi.org/10.1016/j.jretconser.2011.03.003

Qiu, J., Shen, B., Zhao, M., Wang, Z., Xie, B., \& Xu, Y. (2020). A nationwide survey of psychological distress among Chinese people in the COVID-19 epidemic: implications and policy recommendations. General psychiatry, 33(2). https://doi.org/10.1136/gpsych-2020-100213

Radovic, A., Gmelin, T., Bradley, S., et al. (2017). Depressed adolescents' positive and negative use of social media. Journal of Adolescence, 55, 5-15. https://doi.org/10.1016/j.adolescence.2016.12.002

Reply (2021), Covid-19: impact on brands and creativity. Retrieved from https://www.reply.com/it/covid-19-impact-on-brands-and-creativity

Ridings, C. M., \& Gefen, D. (2004). Virtual community attraction: Why people hang out online. Journal of Computer-mediated communication, $\quad 10(1), \quad$ JCMC10110. https://doi.org/10.1111/j.1083-6101.2004.tb00229.x

Ridings, C. M., Gefen, D., \& Arinze, B. (2002). Some antecedents and effects of trust in virtual communities. The journal of strategic information systems, 11(3-4), 271-295. https://doi.org/10.1016/S0963-8687(02)00021-5

Rogers, E. M., \& Bhowmik, D. K. (1970). Homophily-heterophily: relational concepts for communication research. Public Opinion Quarterly, 34(4), 523-538. https://doi.org/10.1086/267838

Rossi, R., Socci, V., Talevi, D., Mensi, S., Niolu, C., Pacitti, F., ... \& Di Lorenzo, G. (2020). COVID-19 pandemic and lockdown measures impact on mental health among the general population in Italy. Frontiers in psychiatry, 11, 790. https://doi.org/10.3389/fpsyt.2020.00790 
Rotter, J. B. (1967). A new scale for the measurement of interpersonal trust. Journal of personality, 35(4), 651-665. https://doi.org/10.1111/j.1467-6494.1967.tb01454.x

Rousseau, D. M., Sitkin, S. B., Burt, R. S., \& Camerer, C. (1998). Not so different after all: A cross-discipline view of trust. Academy of Management Review, 23(3), 393-404. https://doi.org/10.5465/amr.1998.926617

Russell, D., Cutrona, C.E., Rose, J., \& Yurko, K. (1984). Social and emotional loneliness: An examination of Weiss's typology of loneliness. Journal of Personality and Social Psychology, 46(6), 1313-1321. https://doi.org/10.1037/0022-3514.46.6.1313

Şar, A. H., Göktürk, G. Y., Tura, G., \& Kazaz, N. (2012). Is the Internet use an effective method to cope with elderly loneliness and decrease loneliness symptom? Procedia-Social and Behavioral Sciences, 55, 1053-1059. https://doi.org/10.1016/j.sbspro.2012.09.597

Satorra, A., \& Bentler, P. M. (1994). Corrections to test statistics and standard errors in covariance structural analysis, In C. C. Von Eye Clogg (Ed.), Latent variables analysis: Applications for developmental research (pp. 399-419). Thousand Oaks, CA: Sage.

Saud, M., Mashud, M. I., \& Ida, R. (2020). Usage of social media during the pandemic: Seeking support and awareness about COVID-19 through social media platforms. Journal of Public Affairs, 20(4), e2417. https://doi.org/10.1002/pa.2417

Socialbakers (2020). COVID-19 Impact Report. Retrieved from https://www.socialbakers.com/website/storage/2020/04/Socialbakers-COVID-19-Impact-Report.pdf

Statista. (2020). Coronavirus: economic impact in Italy.

Steffes, E. M., \& Burgee, L. E. (2009). Social ties and on-line word of mouth. Internet Research, 19(1), 42-59. https://doi.org/10.1108/10662240910927812

Syrdal, H. A., \& Briggs, E. (2018). Engagement with social media content: A qualitative exploration. Journal of Marketing Theory and Practice, 26(1-2), 4-22. https://doi.org/10.1080/10696679.2017.1389243

Tang, J., Zhang, Y., Sun, J., Rao, J., Yu, W., Chen, Y., \& Fong, A. C. M. (2011). Quantitative study of individual emotional states in social networks. IEEE Transactions on Affective Computing, 3(2), 132-144. https://doi.org/10.1109/T-AFFC.2011.23

Thoits, P. A. (1982). Conceptual, methodological, and theoretical problems in studying social support as a buffer against life stress. Journal of Health and Social Behavior, 23, 145-159. https://doi.org/10.2307/2136511

Trepte, S., Dienlin, T., \& Reinecke, L. (2015). Influence of social support received in online and offline contexts on satisfaction with social support and satisfaction with life: A longitudinal study. Media Psychology, 18(1), 74-105. https://doi.org/10.1080/15213269.2013.838904

Underwood, B., \& Froming, W. J. (1980). The mood Survey: A Personality Measure of Happy and Sad Moods. Journal of Personality Assessment, 44(4). https://doi.org/10.1207/s15327752jpa4404_11

Vazire, S., \& Gosling, S. D. (2004). E-perceptions: personality impressions based on personal websites. Journal of Personality and Social Psychology, 87, 123-132. https://doi.org/10.1037/0022-3514.87.1.123

Vergura, D.T., Luceri, B., \& Zerbini. C. (2021). How does social eWOM shape consumers' behaviour pattern in the fashion sector? In W. Ozuem, \& S. Ranfagni (Ed.), The Art of Digital Marketing For Fashion And Luxury Brands: Marketspaces And Marketplaces. Palgrave Macmillan. To be pubished.

Wellman, B., \& Gulia, M. (1999). The network basis of social support: A network is more than the sum of its ties. In B. Wellman (Ed.), Networks in the global village: Life in contemporary communities (pp. 83-118). Boulder, CO: Westview Press.

Welt, S. R. (1987). The developmental roots of loneliness. Archives of Psychiatric Nursing, 1, 25-32.

World Bank. (2020). The Global Economic Outlook During the COVID-19 Pandemic: A Changed World.

Wu, C., \& Yao, G. (2008). Psychometric analysis of the short-form UCLA Loneliness Scale (ULS-8) in Taiwanese undergraduate students. Personality and Individual Differences, 44, 1762-1771. https://doi.org/10.1016/j.paid.2008.02.003

Zhao, L., Lu, Y., Wang, B., Chau, P. Y. K., \& Zhang, L. (2012). Cultivating the sense of belonging and motivating user participation in virtual communities: A social capital perspective. International Journal of Information Management, 32, 574-588. https://doi.org/10.1016/j.ijinfomgt.2012.02.006 
Zhu, L., Li, H., Wang, F. K., He, W., \& Tian, Z. (2020). How online reviews affect purchase intention: a new model based on the stimulus-organism-response (SOR) framework. Aslib Journal of Information Management, 72(4), 463-488. https://doi.org/10.1108/AJIM-11-2019-0308

\section{Copyrights}

Copyright for this article is retained by the author(s), with first publication rights granted to the journal.

This is an open-access article distributed under the terms and conditions of the Creative Commons Attribution license (http://creativecommons.org/licenses/by/4.0/). 